\title{
Influence of Land Use Land Cover on Cyclone Track Prediction - A Study During Aila Cyclone
}

\author{
K.V.S. Badarinath ${ }^{1}$, D.V. Mahalakshmi ${ }^{*}, 1$ and Satyaban Bishoyi Ratna ${ }^{2}$ \\ ${ }^{1}$ Atmospheric Science Section, Oceanography Division, Atmospheric and Ocean Sciences Group, National Remote \\ Sensing Center, Hyderabad-500625, India \\ ${ }^{2}$ Application Laboratory, Japan Agency for Marine-Earth Science and Technology (JAMSTEC), Yokohama, Japan
}

\begin{abstract}
Land-surface processes are one of the important drivers for weather and climate systems over the tropics. Realistic representation of land surface processes in mesoscale models over the region will help accurate simulation of numerical forecasts. The present study examines the influence of Land Use/ Land Cover Change (LULC) on the forecasting of cyclone intensity and track prediction using Mesoscale Model (MM5). Gridded land use/land cover data set over the Indian region compatible with the MM5 model were generated from Indian Remote Sensing Satellite (IRS-P6) Advanced Wide Field Sensor (AWiFS) for the year 2007-2008. A case study of simulation of 'Aila' cyclone has been considered to see the impact of these two sets of LULC data with the use of MM5 model. Results of the study indicated that incorporation of current land use/land cover data sets in mesoscale model provides better forecasting of cyclonic track.
\end{abstract}

Keywords: Mesoscale model, Cyclone track, Land use/land cover, Satellite data, Aila Cyclone.

\section{INTRODUCTION}

Tropical cyclones and associated storm surges at many places across the globe causes loss of human life and property. Accurate prediction of tropical cyclone track and intensity are challenging task for any operational meteorological agency as it involves using state of the art numerical models and realistic data sets. Land use/Land cover (LULC) is one of the dynamic features that undergo rapid changes due to anthropogenic and associated developmental activities. The land surface processes affect weather through the exchange of heat, moisture, and momentum between the earth's surface and the atmosphere [1]. LULC changes affect the surface wind, temperature and humidity, which in turn affect the planetary boundary layer (PBL) and thus numerical weather forecasting. Cyclones form in tropical seas and population densities are often high in tropical regions. Cyclones constitute a major hazard for a large number of people around the world [2]. Low-pressure systems of cyclone draw their energy from very warm surface waters. As the warm, moist air spirals in toward the centre, the wind speeds increase, reaching their maximum in the region surrounding the almost calm centre of the cyclone. The favorable conditions for the formation of tropical cyclones are sea surface temperature (SST) greater than $26.5^{\circ} \mathrm{C}$ and a deep lower level moist layer and absence of strong vertical shear $[3,4]$. In tropical regions, land use/land cover changes of ecological and climatic significance are currently taking place, such as colonization of marginal

*Address correspondence to this author at the Atmospheric Science Section, Oceanography Division, Atmospheric and Ocean Sciences Group, National Remote Sensing Center, Hyderabad-500625, India; Tel: +040-23884558;

E-mail: mahameteorology@gmail.com lands, deforestation, dry lands degradation, landscape fragmentation and rapid urbanization [5].

Modification of surface parameters from semiarid land conditions to cultivated lands tends to consistently increase the potential for moist convection during daytime heating hours as expressed in the evolution of the PBL structure and the growth of convective available potential energy (CAPE), as well as area-averaged rainfall [6]. Impact of land surface processes on the boundary layer convective processes have been studied by numerous researchers [7,8]. Narisma and Pitman [9] conducted studies on the impact of continentalscale land cover change (LCC) on the Australian climate. Pitman et al., [10] showed that the reduced surface roughness following land cover change largely explains the simulated changes in rainfall by increasing moisture divergence over southwestern Australia and increasing moisture convergence inland. Numerical experiments performed with the MM5 model under different surface roughness conditions and moisture conditions suggested that roughness contrast between land and sea modifies the tropical cyclone track $[11,12]$ (Wong and Chan., 2006; Kimball, 2008). Wong and Chan [11] found that the PBL convergence of the tropical cyclone core could become strongly asymmetric even when the core of cyclone circulation is completely away from the coast. They proposed the surface-induced asymmetric convergence as a factor that affects the asymmetric convective activities of the tropical cyclone core.

The objective of present study is to understand the influence of land use/land cover in predicting cyclone intensity and track using Mesoscale Model (MM5). Land Use/Land Cover (LULC) data over Indian region derived from Advanced Wide Field Sensor (AWiFS) on board Indian Remote Satellite, IRS-P6, was incorporated in the Mesoscale 
Model (MM5) for analysing the 'Aila' cyclone track. The results were compared with model simulation using the US Geological Survey (USGS) LULC data.

\section{DATA SETS AND METHODOLOGY}

\subsection{Model Design}

MM5 version 3 Release 6 (MM5v3.6.0) [13] was used in the study. The non-hydrostatic version employs the terrainfollowing sigma coordinate as in hydrostatic version of the model (i.e., MM4;) [14], but the pressure at the sigma levels are determined from a reference state that is estimated using the hydrostatic equation from a given sea level pressure and temperature with standard lapse rate. This model has versatility to choose the domain region of interest; horizontal resolution; interactive nested domains and with various options to choose parameterization schemes for convection, planetary boundary layer (PBL), explicit moisture; radiation and soil processes. In the model simulations, the MRF scheme for PBL [15], the Simple Ice scheme for Microphysics [16], the Dudhia Cloud scheme [17] for radiation and Grell scheme for cumulus parameterization were used. The details of the options used in this study are given in Table $\mathbf{1}$.

In the present study we used single domain and grid spacing of $27 \mathrm{~km}$. The simulations study herein was initialized at 0000 Universal Time Coordinate (UTC) of 22 May 2009 and integrated up to 1200 UTC of 26May2009. The initial conditions and lateral boundary conditions for the model domain were taken from National Centre for Environmental Prediction Final Analysis (NCEP FNL) data available at $1 \times 1$ degree resolution. This MM5 model sensitivity study was designed to compare effects of different land use data in meteorological simulation. Two sets of experiments were performed, first with the original USGSLULC data sets and second with the AWiFS-LULC dataset over the Indian region.

\subsection{Land Use/Land Cover (LULC) Data}

Fig. (1) shows the USGS and AWiFS generated land use/land cover (LULC) over the Indian region used in MM5 simulations. IRS-P6 AWiFS-LULC data corresponds to 2007-2008 while the USGS-LULC were generated from National Oceanic and Atmospheric AdministrationAdvanced Very High Resolution Radiometer (NOAAAVHRR) data of April, 1992 - March, 1993. USGS data contains 24- categories land use/land cover features at different resolutions of 1-degree, 30, 10, 5, 2-minutes and 30-seconds available in the MM5 model. IRS-P6 AWiFS data derived LULC cover for 2007-08 was used in generating MM5 compatible gridded data files. We have used 10-minutes LU/LC data, which is nearest to the model grid resolution considered in this present study. Irrigation practices over the Gangetic Plains shown in yellow, urbanization in Delhi, Punjab and Rajasthan are some of the major changes in the Northern India which can be noticed in AWiFS-LULC data compared to USGS-LULC data. The changes in LULC affect the surface albedo and soil hydrology, which in turn has large bearing in forecasting from numerical models [18].

\section{SYNOPTIC DESCRIPTION OF TROPICAL CYCL- ONE 'AILA'}

A Severe Cyclonic Storm, 'Aila' experienced over Bay of Bengal during 22-26 May 2009 with an estimated central sea level pressure of $967 \mathrm{hPa}$ and associated maximum wind of 100 to $110 \mathrm{kmph}$. One of the special features of this cyclone, it maintained cyclonic intensity up to 15 hours after the landfall as reported by Indian Meteorological Department (IMD). This cyclone is that it maintained genesis with a low pressure area formed over the southeast Bay of Bengal on the morning of 22 May. It lay over east central and adjoining west central Bay of Bengal and concentrated into a depression at 0600 UTC of 23 May near $16.5^{\circ} \mathrm{N} / 88.0^{\circ} \mathrm{E}$. The depression moved mainly in a northerly direction and intensified into a deep depression at 0300 UTC of 24 May. It continued to move in northerly direction attaining the stage of cyclonic storm at 12 UTC of 24 May and lay centred near $18.5^{\circ} \mathrm{N} / 88.5^{\circ} \mathrm{E}$. The system continued to intensify and attaining the intensity of severe cyclonic storm at 0600 UTC

Table1. Details of the Model Used in this Study

\begin{tabular}{|l|l|}
\hline Model: & Fifth generation Penn State /NCAR Mesoscale Model (MM5) \\
\hline Main prognostic variables: & Non-hydrostatic with three-dimensional Coriolis Force \\
\hline Map projection: & Mercator conformal mapping \\
\hline Central Point of Domain: & $20^{\circ}$ North and $70^{0}$ East \\
\hline Horizontal grid distance: & $27 \mathrm{~km}$ \\
\hline Number of vertical levels: & 23 half sigma levels \\
\hline Horizontal grid system: & Arakawa B grid \\
\hline Time integration scheme: & Leap frog scheme with time-splitting technique \\
\hline Cumulus parameterization scheme: & Grell \\
\hline Radiation parameterization scheme: & Dudhia Cloud \\
\hline PBL parameterization scheme: & MRF \\
\hline Microphysics: & Simple Ice \\
\hline Soil Model: & Multi-layer soil model \\
\hline Land Use/Land Cover & USGS and AWiFS \\
\hline
\end{tabular}




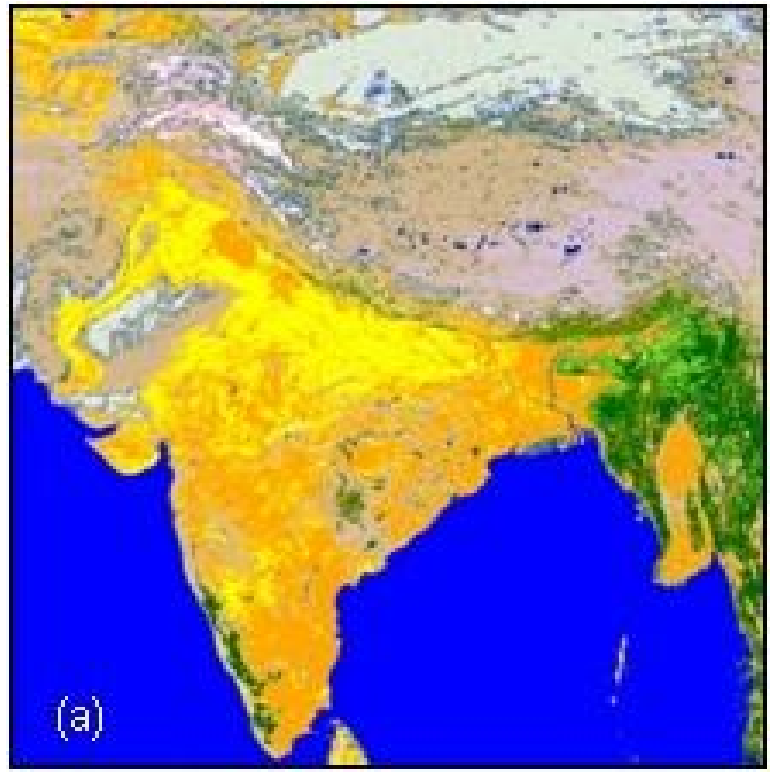

\begin{tabular}{|c|c|}
\hline 1 & Urban \\
\hline 2 & Dryland crop \\
\hline 3 & irrg. Crop \\
\hline 4 & mix Dry /irrCp \\
\hline 5 & Crop/grs Moist \\
\hline 6 & Crop/wood mos \\
\hline 7 & Grassland \\
\hline 8 & Shrubland \\
\hline 9 & Mix Shrub \\
\hline 10 & Savana \\
\hline 11 & DeciBroadll" \\
\hline 12 & DeciNeedf \\
\hline 13 & EvgBroad \\
\hline 14 & EvgNeedflf \\
\hline 15 & mixed Forest \\
\hline 16 & Water bodies \\
\hline 17 & Herb wetland \\
\hline 18 & Wooded wetland \\
\hline 19 & BarSpareVeg \\
\hline 20 & Herb Tundra \\
\hline 21 & Wooden Tundra \\
\hline 22 & Mixed Tundra \\
\hline 23 & Bare Gind Tundra \\
\hline 24 & Snow or ice \\
\hline
\end{tabular}

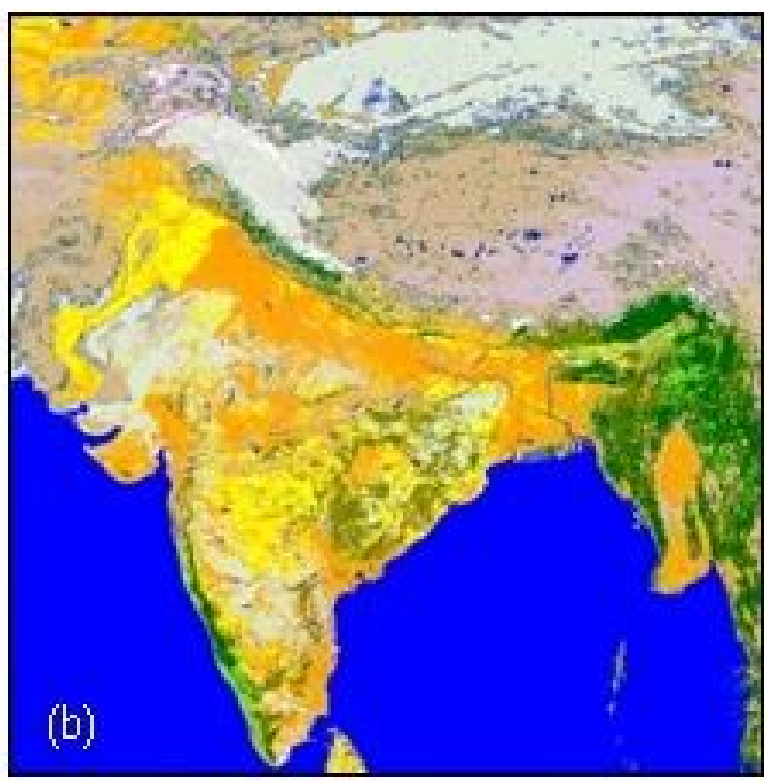

Fig. (1). Land use/land cover data used in the Mesoscale model (a) USGS and (b) AWiFS.

of 25 May and lay centred over northwest Bay of Bengal. System crossed West Bengal coast close to the east of Sagar Island between 0800 and 0900 UTC 25 May as a severe cyclonic storm. After the landfall, the system continued to move in a northerly direction, gradually weakened into a cyclonic storm over Gangetic West Bengal and further weakened into a deep depression over Sub-Himalayan West Bengal and Sikkim. It weakened into a depression at 0600 UTC of 26th May, 2009 over the same region and weakened as a well marked low pressure area over Sub-Himalayan West Bengal and neighbourhood at 0900 UTC of $26^{\text {th }}$ May. Widespread heavy rainfall occurred over Orissa, West Bengal and Sikkim during 25 and 26 May. Heavy to very heavy rainfall also occurred over Assam and Meghalaya on 26th and 27th May. By the time it had finally dissipated, the 'Aila' cyclone had claimed over 275 causalities as well as wreaking havoc upon the standing crops in West Bengal and Bangladesh.

\section{RESULTS AND DISCUSSION}

The results from MM5 model simulations of 'Aila' cyclone over Bay of Bengal during the last week of May, 2009 using AWiFS-LULC and USGS-LULC data simulations were analysed.

\subsection{Sea Level Pressure (SLP) and Wind Direction at 850 hPa}

Fig. (2) shows the model derived sea level pressure variations overlaid by wind direction from USGS-LULC and AWiFS-LULC simulations during the 'Aila' cyclone period. It can be seen from Fig. (2) that, both USGS and AWiFS land use /land cover derived cyclone position and intensity are showing similar patterns when the cyclone system is far away from land. As the cyclone is nearing the land, the position and intensity of system is showing considerable 
22May2009_12UTC
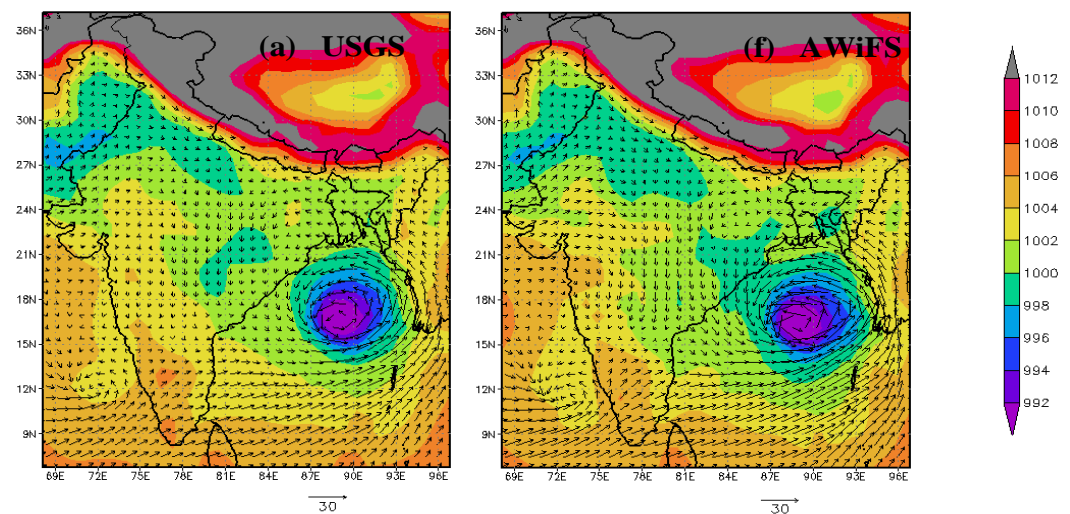

23May2009_12UTC
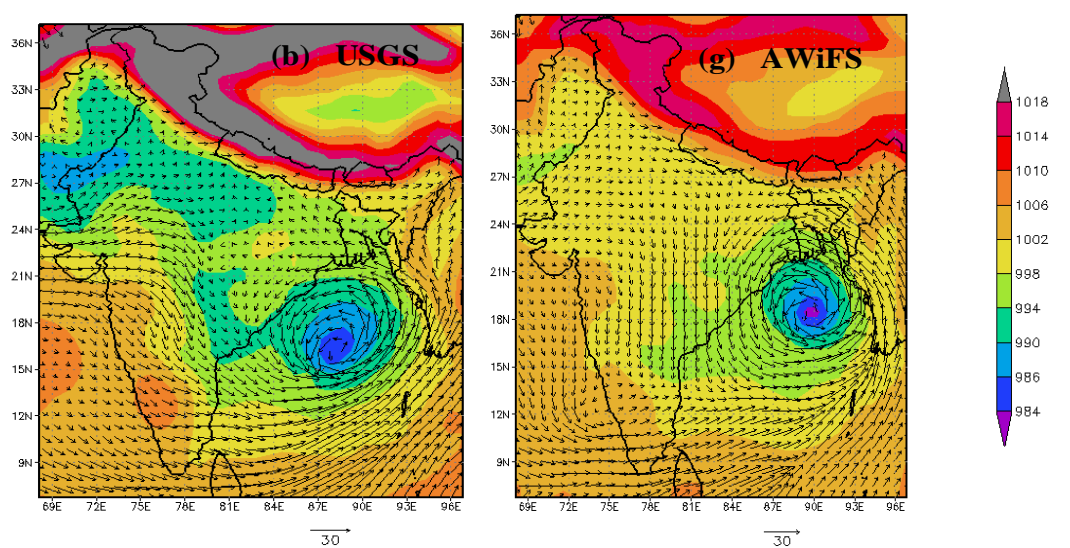

24May2009_12UTC
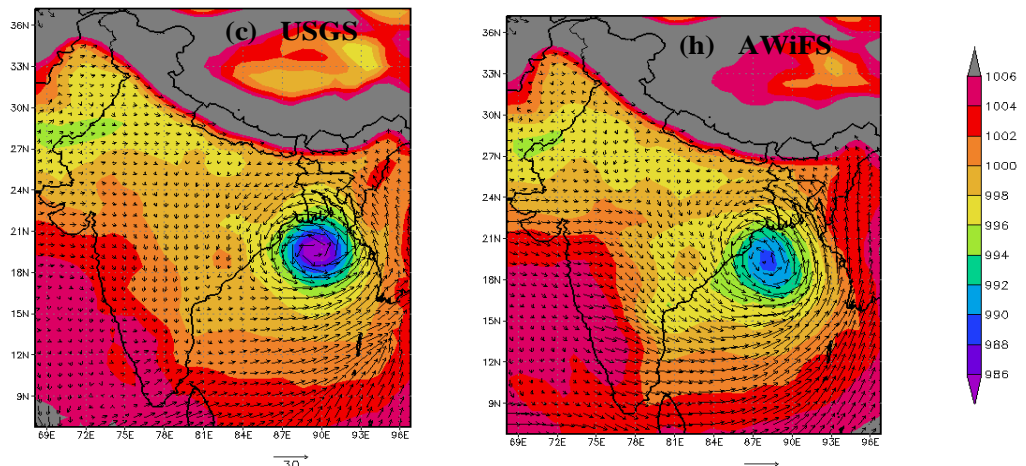

25May2009_09UTC
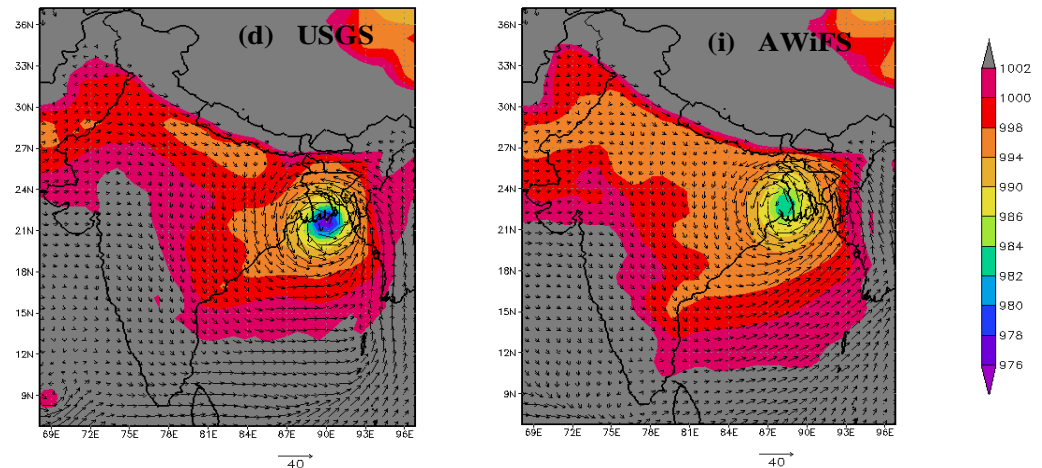

Fig. (2). MM5 Model simulated sea level pressure (hPa) and $850 \mathrm{hPa}$ Wind fields during 'Aila' cyclone over Bay of Bengal on different time periods. (a-d) USGS, (f-i) AWiFS. 
difference between AWiFS simulation and USGS simulation. The changes in wind structure and cyclone track in AWiFS simulation as the cyclone is nearing the coast were attributed to changes in surface roughness. The boundary layer winds are weak over the land compared to sea at the time of cyclone resulting in strong asymmetry in the surface fluxes of heat, moisture and momentum. The incorporation of current land use/land cover data from IRSP6 AWiFS in the MM5 model could provide realistic representation of surface roughness. The land surface roughness forces an asymmetry of the near surface wind by reducing it over the land resulting in large scale asymmetric convergence/divergence along the coast. In addition, the land surface also modulates the air flow across land to sea. The combined effects of this asymmetry modify the potential vorticity resulting in drift in tropical cyclone track. The MM5 model simulations with different surface roughness conditions by Wong and Chan [11] showed considerable drift in tropical cyclone position with changes in surface roughness. The increase in surface roughness decreases the cyclone intensity during land fall as reflected in reduced cyclone central pressure in Fig. (2c, d). Further, increase in land surface roughness causes changes in air circulation through local convergence and divergence resulting in increased wind speed as seen in Fig. (2f-h). Earlier studies in literature on sensitivity of cyclone track on land use/land cover also suggested that surface roughness and soil moisture play an important role in predicting the actual track of the cyclone [19-25].

\subsection{Track}

Fig. (3) shows cyclone track position derived using Joint Typhoon Cyclone Warning Centre (JTWC) and MM5 model simulations with USGS LULC data and AWiFS LULC data respectively. Both experiment shows northerly movement of the cyclone for the first 12 hours and close to JTWC position. After first 12 hours, the USGS predicted tracks show movement towards east showing increase in track error and then towards north up to landfall and lying far away from the JTWC observed track. However, AWiFS predicted track is moving west after first 12 hours of simulation and then moving towards north and coinciding with JTWC track. The USGS cyclone show 6 hours late land fall compared to JTWC observation and AWiFS simulation. The AWiFS simulated track show straight northerly movement but USGS track show the zigzag path of cyclone and so making delay in landfall. This figure depicts that the MM5-AWiFS derived track positions are matching well with actual track of JTWC. This suggests that incorporation of current land use/land cover data in mesoscale model plays an important role in cyclone track prediction. The errors in cyclone track prediction were considerably reduced with AWiFS LULC data in mesoscale model compared to USGS (Fig. 3).

The near surface wind deviates as per the surface characteristics of the land surface. As wind over land reduced causes large scale convergence/divergence along the coast, Also, air flowing offshore needs time to adjust to the sea surface, and vice versa [11]. These mechanisms depend on the roughness contrast between land and sea and to be the cause of the cyclone drift, since they could modify the potential vorticity tendency.

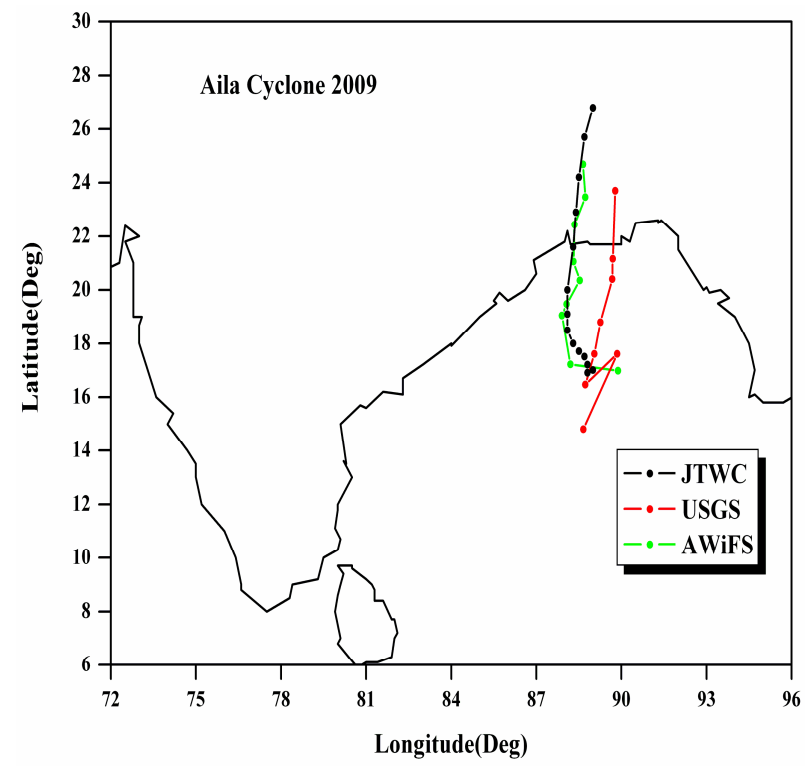

Fig. (3). Mesoscale model simulated cyclone track from using USGS data, AWiFS data and JTWC at six hourly time periods from 23May2009_00UTC to 26May2009_00UTC.

\subsection{Time Series of Minimum Sea Level Pressure and Maximum Wind Speed}

Fig. (4) shows the central pressure of the cyclone and maximum sustained wind speed from different model simulations compared with JTWC observations. The model simulated minimum central surface pressure variation with time show the pre-deepening, deepening and decay stages of the cyclone. The results indicating that the time variation of central pressure is quite close to JTWC value throughout the cyclone. AWiFS cyclone shows higher intensity in terms of central pressure for the first 24 hours as compared to the USGS and then after shows close agreement with JTWC intensity. The deepening and decaying stage of cyclone with AWiFS is matching with JTWC value. The USGS value shows more intense compared to JTWC value up to 1800 UTC of 24 May. The AWiFS shows the deepening of cyclone between 0000 UTC of 24 May to 1200 UTC of 25 May. However, USGS started deepening of the cyclone at 0000 UTC of 23 May and continued its intensity until the landfall. The sudden deepening of the cyclone at 0000 UTC of 25 May is better simulated with USGS compared to the AWiFS. Even though the deepening period of the model cyclone coincides with observation, it couldn't attain the maximum intensity compared to JTWC value. The interaction of model cyclone with surface boundary and the environmental flow could have helped for the correct deepening period of the cyclone. The observed cyclone started decaying after 0600 UTC of 25 May and AWiFS cyclone is closely following to JTWC observation. However, USGS cyclone is continuing its intensity after the landfall though it reduced its strength after landfall.

The time variation of the model simulated maximum sustained wind speed (MW) is shown in the Fig. (4b). This shows the close agreement between AWiFS and JTWC wind. The USGS shows higher intensity of the cyclone 

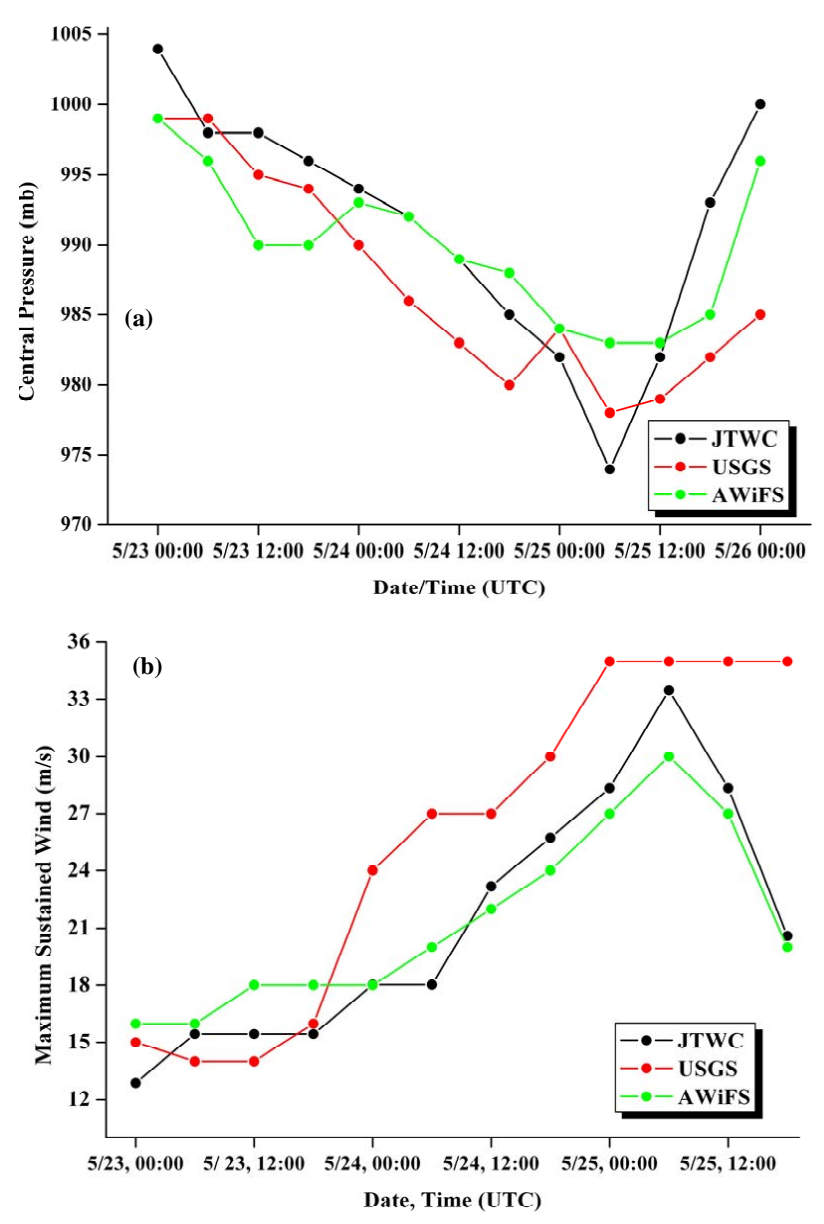

Fig. (4). Comparison of (a) 'Aila' Cyclone central pressure (b) Maximum Sustained Wind Speed fromMM5 model simulations with USGS, AWiFS-LULC data and JTWC.

throughout the period except for the first few hours. The model could predict the values of MW as 35 and $30 \mathrm{~m} / \mathrm{s}$ for USGS and AWiFS experiment compared to $33 \mathrm{~m} / \mathrm{s}$ in the observation. For the first 18 hours both the simulation and observations maintaining uniform wind speed and increase there after to attain the maximum intensity. The sudden deepening of the cyclone in terms of MW with USGS is 6 hours earlier than AWiFS simulation. This USGS also shows the early time of attaining maximum wind speed compared to observation and AWiFS simulation. The USGS data based model simulation does not show any decaying stage of cyclone after reaching to its maximum wind. However, the AWiFS shows the decaying stage of cyclone after the 06 UTC of 25 May and having close agreement with observation. It can be seen from the figure that incorporation of current land use/land cover data from AWiFS improves the pressure and wind variations as surface roughness was better represented.

Tropical cyclones are driven by heat fluxes from the ocean and quickly dissipate after moving over land or cold water. The heat flux from the sea is mostly in the form of a latent heat flux that accompanies evaporation of seawater into the overlying atmosphere. The representation of air-sea heat flux exchange during a tropical cyclone is of importance for accurate modeling of the atmosphere or ocean. Figs. (5, 6) shows model derived day average sensible and latent heat flux using USGS and AWiFS land use/land cover data. The significant differences of heat fluxes are observed in both the experiments especially over central India and northwest India. It was observed that the heat fluxes with AWiFS are high over Bangldesh compared to USGS. This is the region, where cyclone is made landfall. However, the fluxes are high over north bay of Bengal (off the coast of Bangladesh) in the USGS compared to AWiFS. The partitioning of energy fluxes with current AWiFS derived land use/land cover show marked variation compared to USGS. This may be due to changes in land use/land cover which results in modification of albedo values, moisture availability and surface roughness [12]).

\section{CONCLUSIONS}

In the present study, influence of land use/land cover on cyclone track prediction were analysed using IRS-P6 AWiFS derived Land use/Land cover (LULC) data and USGS LULC data. Numerical simulations were performed by varying the two sets of land use data in the mesoscale model to study its influence on the cyclone track prediction. Results of the study suggested that realistic representation of surface features is important as land surface roughness and moisture availability plays a pivotal role in for cyclone track forecasting. The position and intensity of the cyclone system is showing considerable difference between AWiFS LULC based simulation and USGS LULC based simulation as the cyclone is close to the coast and these changes occur due to the changes in surface roughness and moisture availability. Also, there is a difference in the boundary layer winds over the ocean and land. These winds were weak over land compared to sea resulting in changes in surface heat fluxes, moisture and momentum. From a comparative study on the performance of the two sets of land use data in a mesoscale models for the simulation of Aila tropical cyclone over Bay of Bengal, the following broad conclusions can be derived. Both the simulations could reproduce most of the features of the cyclones but the results with AWiFS are having close agreement with observations. The intensity of cyclone in terms of central pressure and maximum sustainable wind illustrates that model simulation with USGS data has a tendency to intensify the system earlier than observation. Model simulation with AWiFS LULC data gives reasonably good results for the time variation of SLP and wind, which are closer to the observations. This is preliminary result with a single case study and further attempts are in progress to consider more case studies with different cyclone intensity to understand the influence of land use/land cover. In general regional model exhibits internal variability that sometime depends on model configuration. To check the robustness of the LULC changes factor in the MM5 simulation, the authors will attempt to consider the impact of internal variability as a future work which will include the sensitivity of initial conditions, model start time and physical parameterization schemes.

\section{ACKNOWLEDGEMENTS}

The authors thank Director, NRSC and DD (RS\&GISAA), NRSC for their encouragement and ISRO-ASP for funding support. The authors thank Mr. M. Sivaprasad Reddy, Mr. M.Y. Aslam, Mr. M. Nareshkumar and Mr. Biswadip Gharai for their help. The authors thank team members of National AWiFS based land use/land cover mapping project. 


\section{May2009}
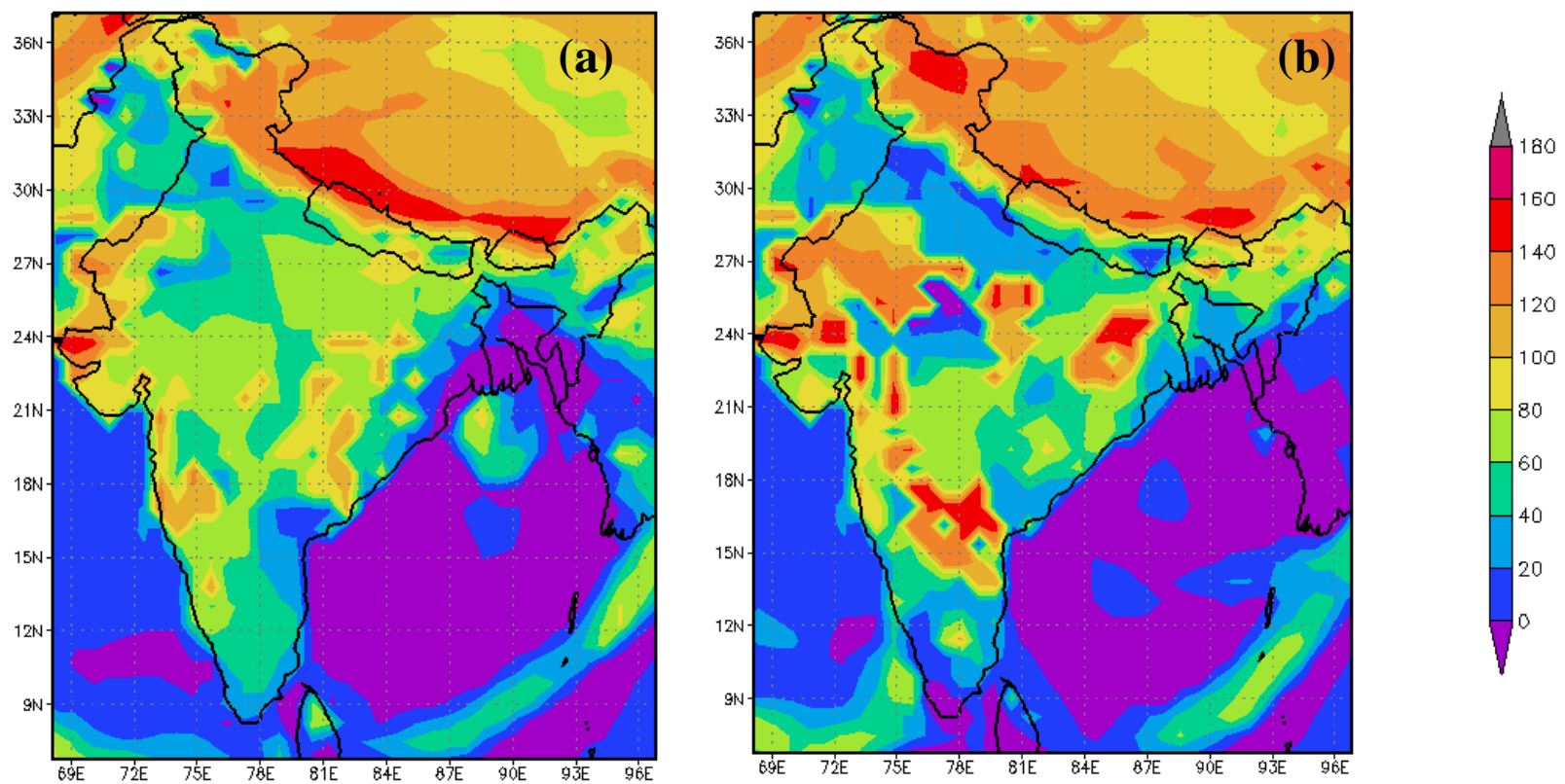

\section{May2009}
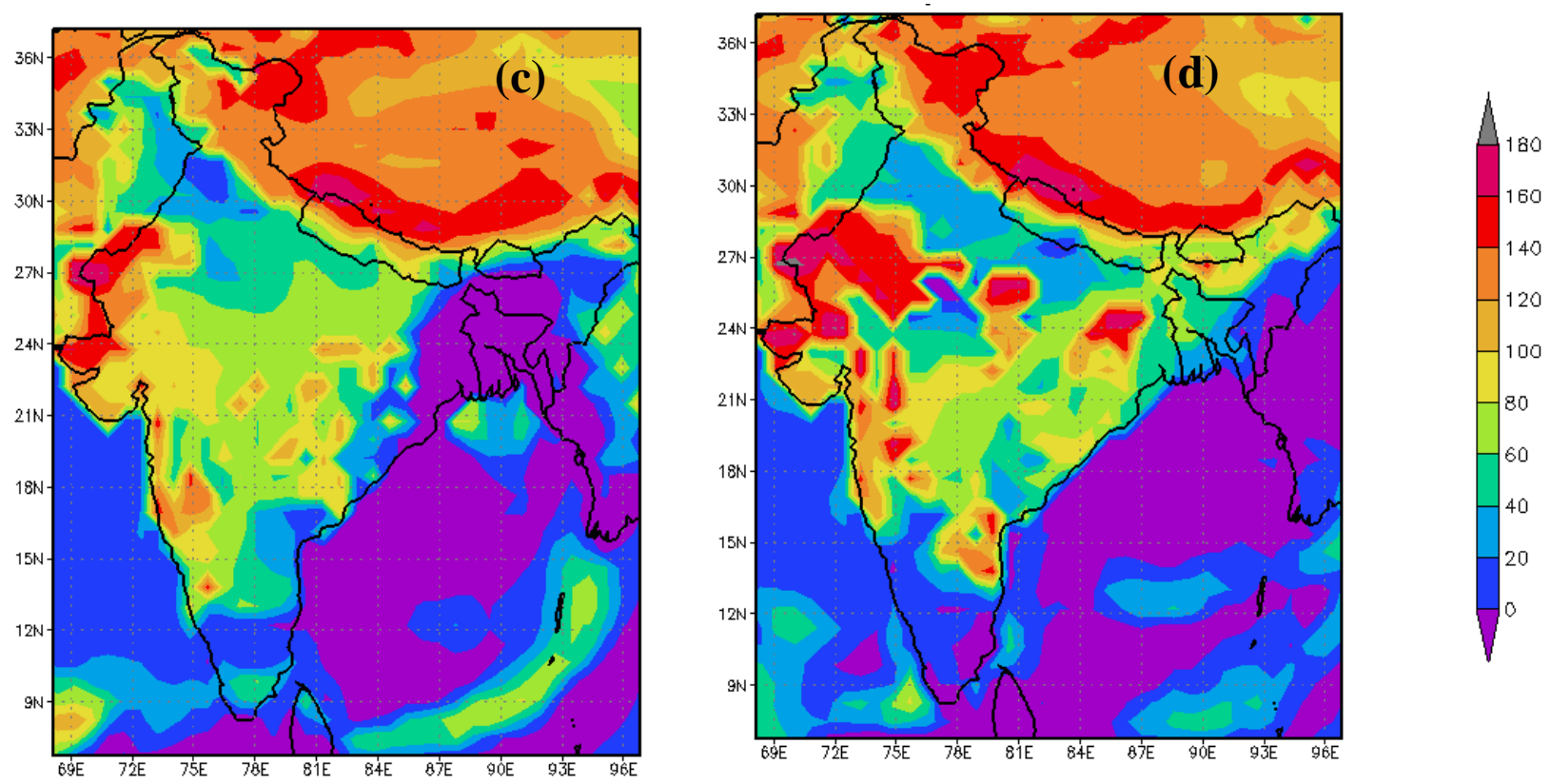

Fig. (5). Comparison of mesoscale model derived Sensible Heat Flux (W/m²) with (a) USGS (b) AWiFS land use/land cover data for 24May2009 and (c)USGS (d) AWiFS for 25May2009. 


\section{May2009}
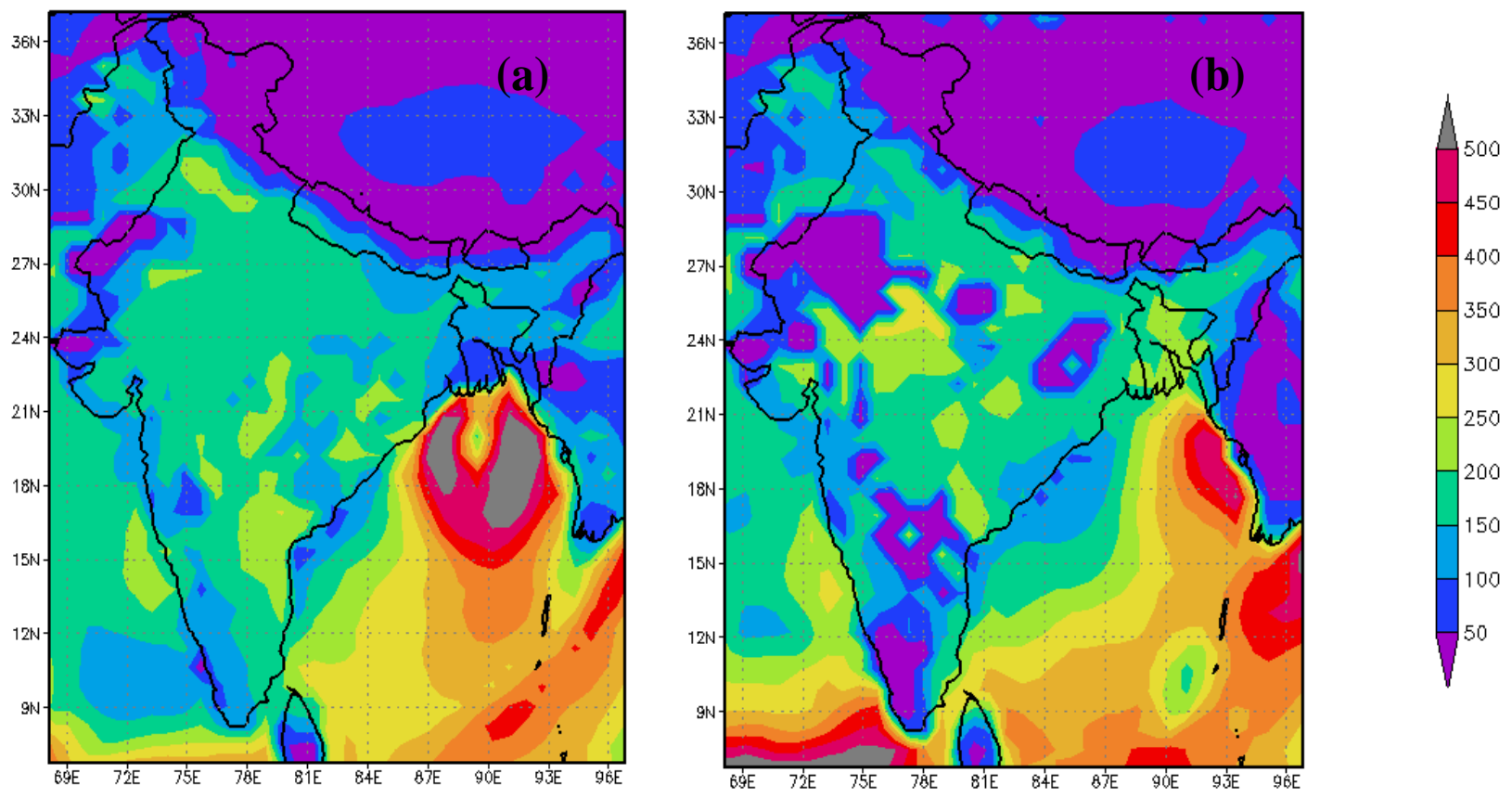

\section{May2009}
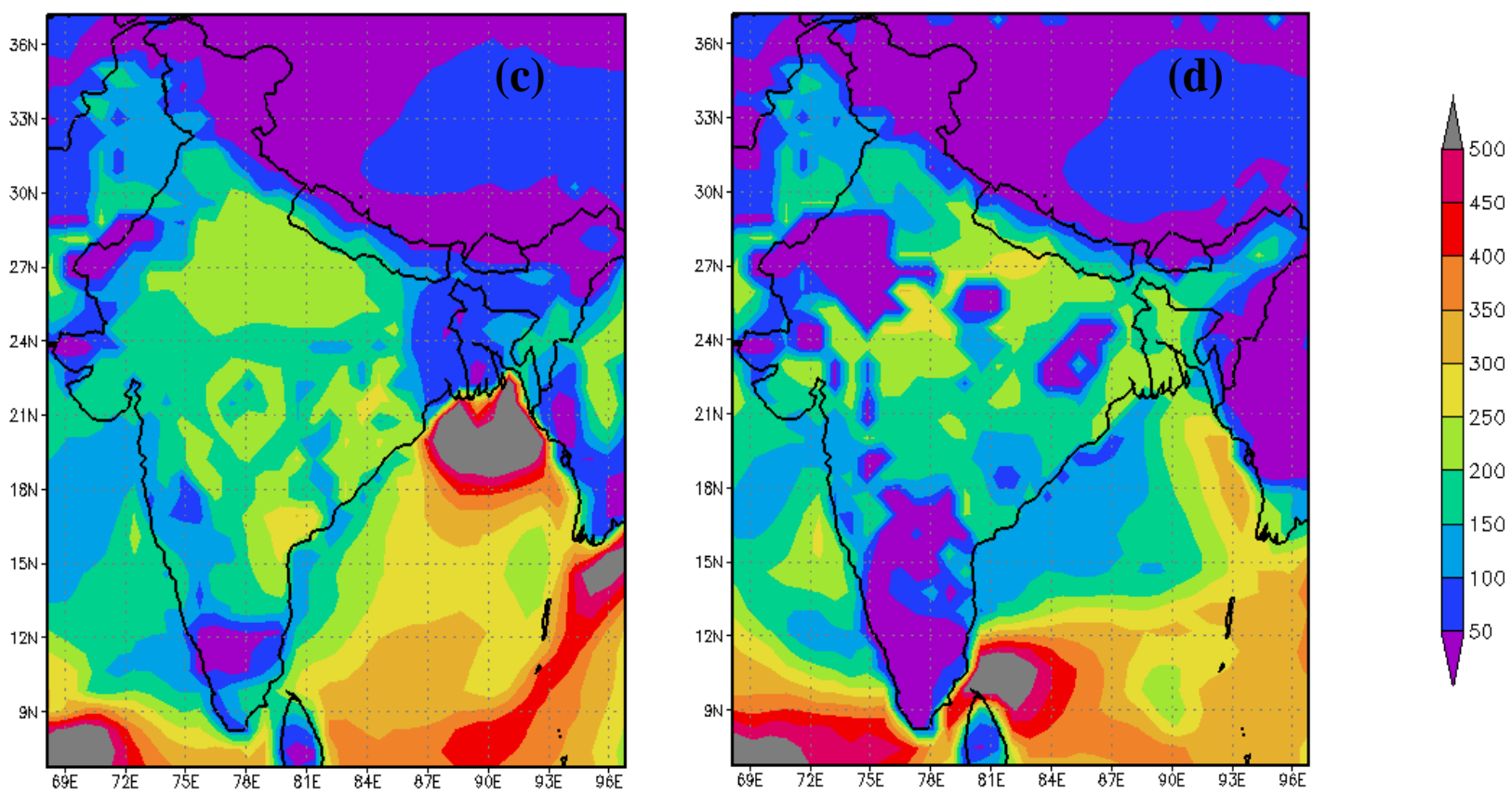

Fig. (6). Comparison of mesoscale model derived Latent Heat Flux (W/m²) with (a) USGS (b) AWiFS land use/land cover data for 24May2009 and (c)USGS (d) AWiFS for 25May2009. 


\section{CONFLICT OF INTEREST}

None declared

\section{REFERENCES}

Betts AK, Ball JH, Beljaars ACM, Miller MJ, Viterbo PA. The land surface-atmosphere interaction: a review based on observational and global modeling perspectives. J Geophys Res 1996; 101(B): 7209-25.

[2] Cerveny RS, Newman LE. Climatologically relationships between tropical cyclones and rainfall. Mon Weather Rev 2000; 128 (9): 3329-36.

[3] Gray WM. Tropical cyclone formation and intensity change; In: Tropical Cyclone Disasters, Eds. James Lighthill, Greg Holland, Zheng Zhemin and Keny Ommanuel, Peking University Press 1992.

[4] Frank WM. The structure and energetics of the tropical cyclone II: Dynamics and energetic. Mon Weather Rev 1977; 105: 136-50.

[5] Lambin EF. Monitoring forest degradation in tropical regions by remote sensing: some methodological issues. Glob Ecol Biogeograph 1999; 8: 191-8.

[6] Nataly P, Pinhas A. Effect of land use modification on potential increase of convection: a numerical mesoscale study over south Israel. J Geophys Res 2001; 106: 621-34.

[7] Anthes RA. Enhancement of convective precipitation by mesoscale variation in vegetative covering in semiarid regions. $J$ Appl Meteorol 1984; 23: 541-54.

[8] Collins DC, Avissar R. An evaluation with the fourier amplitude sensitivity test (FAST) of which land surface parameters are of greatest importance in atmospheric modeling. J Clim 1994; 7: 681703.

[9] Narisma GT, Pitman AJ. The impact of 200 years land cover change on the Australian near-surface climate. J Hydrometeorol 2003; 4: 424-36.

[10] Pitman AJ, Narisma GT, Pielke Sr RA, Holbrook NJ. Impact of land cover change on the climate of southwest Western Australia. J Geophys Res 2004; 109: 1-12.

[11] Wong MLM, Chan JCL. Tropical cyclone motion in response to Land surface friction. J Atmos Sci 2006; 63: 1324-37.
[12] Kimball Sytske K. Structure and evolution of rainfall in numerically simulated landfalling hurricanes. Mon Wea Rev 2008; 136: 3822-47. doi: 10.1175/2008MWR2304.1.

[13] Grell GA, Dudhia J, Stauffer DR. A description of the fifth generation of penn state/NCAR Mesoscale Model (MM5); NCAR Tech. Note NCAR/TN-398+STR, 1994; 117p.

[14] Anthes RA, Hsie EY, Kuo YH. Description of the Penn State/ NCAR mesoscale model version 4 (MM4). NCAR Tech. Note NCAR/TN-282, 1987; 66.

[15] Hong SY, Pan HL. Nocturnal boundary layer vertical diffusion in a medium-range forecast model. Mon Weather Rev 1996; 124: 2322 39.

[16] Schultz P. An explicit cloud physics parameterization for operational numerical weather prediction. Mon Weather Rev1995; 123: $3331-43$.

[17] Dudhia J. Numerical study of convection observed during the winter monsoon experiment using a mesoscale two-dimensional model. J Atmos Sci 1989; 46: 3077-107.

[18] Pielke RA. Interactions between the atmosphere and terrestrial ecosystems: influence on weather and climate. Glob Change Biol 1998; 4: 461-75.

[19] Krishnamurti TN, Jha B. Cyclone track prediction. Sadhana1998; 23: $653-84$

[20] Tuleya RE. Tropical storm development and decay: sensitivity to surface boundary conditions. Mon Weather Rev 1994; 122: 291304.

[21] Shen W, Ginis I. A numerical investigation of land surface water on land falling hurricanes. J Atmos Sci 2002; 59(4): 789-802.

[22] Vinodkumar Chandrasekar A, Dev Niyogi, Alapaty K. Impact of land surface representation and surface data assimilation on the simulation of an off-shore trough over the Arabian Sea. Glob Planet Change 2009; 67: 104-16.

[23] Ping Zhu. Impact of land-surface roughness on surface winds during hurricane landfall. QJR Meteorol Soc 2008; 134: 1051-7.

[24] Dabberdt WF, Hales J, Zubrick S, et al. Forecast issues in the urban zone: report of the $10^{\text {th }}$ prospectus development team of the U.S weather research program. Bull Am Meteorol Soc 2000; 81: 204764.

[25] Claussen M. Ed, Does landsurface matter in climate and weather? in vegetation, water, humans and the climate: a new perspective on an interactive system, part A: a synthesis of the IGBP Core Project. Biospher Asp Hydrologic Cycle 2002. 